\title{
Hubungan antara chronotype dengan tingkat gejala depresi pada mahasiswa kedokteran tingkat pertama di Fakultas Kedokteran Universitas Tanjungpura
}

\author{
Anisa Faradiba Ratrin 1,*, Wilson², Muhammad In'am Ilmiawan ${ }^{3}$ \\ ${ }^{I}$ Program Studi Kedokteran, Fakultas Kedokteran, Universitas Tanjungpura, Kalimantan Barat, Indonesia \\ ${ }^{2}$ Departemen Ilmu Kesehatan Jiwa, Rumah Sakit Jiwa Kota Singkawang, Kalimantan Barat, Indonesia \\ ${ }^{3}$ Departemen Biologi dan Patobiologi, Fakultas Kedokteran, Universitas Tanjungpura, Kalimantan Barat, Indonesia \\ *Korespondensi: anizhafarad@gmail.com
}

\begin{abstract}
Abstrak
Latar belakang: Chronotype merupakan preferensi biologis seseorang dalam memilih jam tidur dan waktu aktif (bangun) yang terbagi menjadi dua tipe yaitu morningness dan eveningness. Mahasiswa dengan tuntutan akademik serta non-akademik yang tinggi cenderung untuk memiliki preferensi eveningness. Dalam aspek psikis, chronotype eveningness dinilai turut berperan terhadap kejadian gangguan emosi, salah satunya yaitu depresi. Penelitian menilai hubungan antara chronotype dengan tingkat gejala depresi pada mahasiswa kedokteran tingkat pertama di Fakultas Kedokteran Universitas Tanjungpura. Metode: Ini adalah studi observasional analitik dengan pendekatan cross-sectional dan teknik total sampling. Sebanyak 97 mahasiswa tingkat pertama menjadi responden penelitian. Morningness-Eveningness Questionnaire dan Beck Depression Inventory-II digunakan sebagai alat ukur. Analisis data dilakukan menggunakan Uji Chi-square. Hasil: Responden yang memiliki chronotype morningness dan tidak memiliki gejala depresi sebanyak 35 mahasiswa (36\%), sedangkan yang memiliki gejala depresi sebanyak 4 mahasiswa (4\%). Responden yang memiliki chronotype eveningness dan tidak memiliki gejala depresi sebanyak 19 mahasiswa (20\%) sedangkan yang memiliki gejala depresi sebanyak 39 mahasiswa (40\%). Berdasarkan uji statistik didapatkan nilai p=0,000. Kesimpulan: Terdapat hubungan antara chronotype dengan tingkat gejala depresi pada mahasiswa kedokteran tingkat pertama di Fakultas Kedokteran Universitas Tanjungpura.
\end{abstract}

Kata kunci: chronotype, circadian, depresi, mahasiswa

\section{Correlation between chronotype and degree of depressive symptoms among first-year medical students at Faculty of Medicine Tanjungpura University}

\begin{abstract}
Background: Chronotype is a person's biological preference in selecting sleep and active hours. There are two types of chronotype: morningness and eveningness. Students with high academic and non-academic stress tend to have eveningness. In psychological aspects, eveningness is considered to contribute to mental health problems such as depression. This study evaluated the correlation between chronotype with degree of depressive symptoms among first-year medical students at Faculty of Medicine Tanjungpura University. Methods: This was an analytical observational study using cross-sectional design and total sampling technique. Ninety-seven students were included in the study. Morningness-Eveningness Questionnaire and Beck Depression Inventory-II were used to collect the data. Data were analyzed using Chi-square test. Results: Thirty-five students who had morningness didn't have depressive symptoms (36\%), while four students had depressive symptoms (4\%). Nineteen students who had eveningness didn't have depressive symptoms (20\%), while 39 students had depressive symptoms (40\%). Statistical tests showed p-value of 0.000 . Conclusions: There is correlation between chronotype with degree of depressiove symptoms among first-year medical students at Faculty of Medicine Tanjungpura University.
\end{abstract}

Keywords: chronotype, circadian, depression, students 


\section{Pendahuluan}

Tidur merupakan kebutuhan dasar bagi manusia. Tidur didefinisikan sebagai suatu keadaan tidak sadar yang mana individu tersebut dapat dibangunkan kembali melalui stimulus atau sensor yang berkaitan dengannya. ${ }^{1}$ Setiap individu memiliki pola-pola tidur tersendiri dimana ada individu yang memiliki preferensi tidur di awal malam ada pula yang memiliki preferensi tidur di larut malam. Adanya perbedaan ini merupakan efek pada chronotype. ${ }^{2}$

Chronotype didefinisikan sebagai preferensi biologis individu dalam memilih waktu tidur dan waktu dalam memulai aktivitas (bangun). ${ }^{3}$ Chronotype diklasifikasikan menjadi dua yaitu morningness (tipe pagi) dan eveningness (tipe malam). Morningness merupakan kecenderungan untuk bangun awal di pagi hari dengan performa mental, fisik, dan konsentrasi terbaik saat pagi hari. Sedangkan tipe eveningness memiliki kecenderungan untuk terjaga di malam hari dan bangun terlambat dibandingkan tipe morningness dengan performa mental, fisik, dan konsentrasi terbaik saat petang hingga malam. ${ }^{4}$

Menurut penelitian yang telah dilakukan oleh Adan dan Natale, dalam rentang usia 17-81 tahun, ditemukan $83 \%$ wanita berorientasi morningness sedangkan pria berorientasi morningness sebesar $61 \%$. Penemuan ini menunjukkan bahwa wanita lebih berorientasi morningness dibandingkan pria. ${ }^{5}$

Pada eveningness terjadi ketidakselarasan antara kebutuhan jumlah jam tidur yang ideal dengan jam social. Individu dengan aktivitas malam yang tinggi memiliki kecenderungan eveningness akibat adanya aktivitas terjaga di malam hari secara terus-menerus sehingga menyebabkan terganggunya jam tidur ideal dengan kualitas tidur yang buruk. ${ }^{6}$

Individu dengan eveningness terpaksa bangun awal seperti tipe morningness demi mengikuti jam sosial pada umumnya, sehingga dampak dari kurangnya jumlah jam tidur tersebut merupakan faktor pendukung penyebab terjadinya gangguan mental seperti depresi. ${ }^{7}$ Individu dengan eveningness berisiko $6 \%$ lebih tinggi mengalami gangguan psikologis seperti depresi dan kecemasan dibandingkan tipe morningness. ${ }^{8}$ Berdasarkan penelitian yang dilakukan oleh Reid et al, perbandingan penderita gangguan depresi dan eveningness adalah $7: 4 .^{9}$

Depresi merupakan gangguan suasana hati atau mood yang ditandai dengan adanya perasaan sedih, kehilangan minat atau kesenangan, perasaan bersalah atau merasa tidak berharga, rasa percaya diri yang rendah yang pada umumnya disertai dengan gangguan somatik atau kognitif sehingga mengganggu kualitas hidup penderitanya. ${ }^{10}$ Depresi dinilai sebagai salah satu gangguan kejiwaan yang paling sering ditemukan di berbagai negara dan dapat menyebabkan perubahan pada kualitas hidup seseorang. Depresi juga menjadi faktor pendukung tingginya angka morbiditas dan mortalitas di dunia. ${ }^{11}$ World Health Organization menyebutkan bahwa pada tahun 2017 lebih dari 50 juta orang di dunia mengalami gangguan depresi. Sedangkan di Indonesia lebih dari 9 juta masyarakat mengalami gangguan depresi. Dengan besarnya angka ini menyebabkan Indonesia menempati peringkat kedua sebagai negara dengan penderita gangguan depresi tertinggi setelah India di Asia Tenggara. ${ }^{11}$ Prevalensi depresi di Kalimantan Barat menurut Riskesdas 2018 adalah sebesar $6,1 \% .^{12}$

Depresi pada mahasiswa kedokteran telah menjadi isu kesehatan yang serius bagi sekolah kedokteran di seluruh dunia. Berdasarkan penelitian yang dilakukan oleh Torphy et al, menyatakan sebanyak 27\% mahasiswa kedokteran di 47 negara mengalami depresi beserta gejalanya, sementara $11 \%$ lainnya berpikiran untuk melakukan bunuh diri selama kuliah. ${ }^{13}$ Sedangkan pada penelitian yang dilakukan di Indonesia, jumlah mahasiswa kedokteran yang mengalami depresi menunjukkan angka prevalensi sebesar $34,9 \% .^{14}$ Selain itu, penelitian yang dilakukan pada mahasiswa Program Studi Kedokteran Fakultas Kedokteran Universitas Tanjungpura tahun 2014 didapatkan sebanyak 30,8\% mahasiswa mempunyai gejala depresi dengan rincian yaitu 15,4\% mengalami depresi ringan, $13 \%$ depresi sedang, dan $2,4 \%$ depresi berat. Sedangkan pada angkatan 2012 ditemukan persentase depresi sebesar $39,4 \%$, dan angkatan 2011 sebanyak $18,7 \%{ }^{15}$

Berdasarkan penelitian yang dilakukan oleh Shams et al, tahun pertama studi memiliki pengaruh pada prevalensi angka kejadian depresi terbanyak, di antara tahun studi setelahnya. Dari total mahasiswa yang mengalami depresi 48,4\% merupakan mahasiswa tingkat pertama. ${ }^{16}$

Berdasarkan tinjauan di atas, maka penulis sangat tertarik untuk mencari tahu apakah terdapat hubungan antara chronotype dengan tingkat gejala depresi pada mahasiswa tingkat pertama Program 
Studi Kedokteran Fakultas Kedokteran Universitas Tanjungpura.

\section{Metode}

Penelitian ini dilakukan di Fakultas Kedokteran Universitas Tanjungpura pada bulan Juli 2019. Penelitian observasional analitik dengan pendekatan cross-sectional dan teknik sampling total sampling. Sebanyak 97 mahasiswa tingkat pertama memenuhi kriteria restriksi. Morningness-Eveningness Questionnaire dan Beck Depression Inventory II digunakan sebagai alat ukur. Analisis data dilakukan menggunakan uji Chi-square.

\section{Hasil}

Berdasarkan tabel 1, sebagian besar responden berjenis kelamin perempuan $(70 \%)$ dan didominasi oleh kategori usia 18 tahun (56\%). Dari aspek preferensi chronotype dapat dilihat bahwa sebanyak $60 \%$ responden memiliki chronotype eveningness. Selain itu, responden paling banyak memiliki tingkat gejala depresi normal $(56 \%)$.

Tabel 1. Karakteristik subjek penelitian

\begin{tabular}{lcc}
\hline \multicolumn{1}{c}{ Karakteristik } & Jumlah & Persentase \\
\hline Jenis kelamin & & \\
Laki-laki & 29 & 30 \\
Perempuan & 68 & 70 \\
Usia (tahun) & & \\
17 & 3 & 3 \\
18 & 54 & 56 \\
19 & 34 & 35 \\
20 & 5 & 5 \\
21 & 1 & 1 \\
Chronotype & & \\
Morningness & 39 & 40 \\
Eveningness & 58 & 60 \\
Depresi & & \\
Normal & 54 & 56 \\
Ringan & 29 & 30 \\
Sedang & 7 & 7 \\
Berat & 7 & 7 \\
\hline (Sumber: Data Primer Juni 2019) & &
\end{tabular}

Distribusi responden berdasarkan chronotype dan jenis kelamin dapat dilihat pada tabel 2. tersebut dapat disimpulkan bahwa persentase terbesar adalah responden yang memiliki preferensi eveningness dan berjenis kelamin perempuan dengan jumlah 45 mahasiswa (46\%).
Tabel 2. Distribusi responden berdasarkan chronotype dan jenis kelamin

\begin{tabular}{llcl}
\hline \multicolumn{4}{c}{ Jenis kelamin } \\
\hline Chronotype & Laki-laki & Perempuan & Total \\
Morningness & $16(17 \%)$ & $23(24 \%)$ & $39(40 \%)$ \\
Eveningness & $13(13 \%)$ & $45(46 \%)$ & $58(60 \%)$ \\
Total & $29(30 \%)$ & $68(70 \%)$ & $97(100 \%)$ \\
\hline
\end{tabular}

Uji Fisher: nilai $\mathrm{p}=0,027$ (Sumber: Data primer Juni 2019)

Distribusi responden berdasarkan tingkat depresi dan jenis kelamin dapat dilihat pada tabel 3 . Berdasarkan data tersebut dapat disimpulkan bahwa persentase terbesar adalah responden yang memiliki tingkat gejala depresi normal dan berjenis kelamin perempuan dengan jumlah 34 mahasiswa (35\%).

Tabel 3. Distribusi responden berdasarkan tingkat depresi dan jenis kelamin

\begin{tabular}{lccc}
\hline \multicolumn{3}{c}{ Jenis kelamin } \\
\hline Tingkat depresi & Laki-laki & Perempuan & Total \\
\hline Normal & $20(21 \%)$ & $34(35 \%)$ & $54(56 \%)$ \\
Ringan & $6(6 \%)$ & $23(24 \%)$ & $29(30 \%)$ \\
Sedang & $2(2 \%)$ & $5(5 \%)$ & $7(7 \%)$ \\
Parah & $1(1 \%)$ & $6(6 \%)$ & $7(7 \%)$ \\
Total & $29(30 \%)$ & $68(70 \%)$ & $97(100 \%)$ \\
\hline
\end{tabular}

Uji Fisher: nilai $p=0,033$ (Sumber: Data primer Juni 2019)

Hubungan chronotype dengan tingkat depresi ditunjukan oleh tabel 4. Persentase terbesar adalah responden dengan chronotype morningness dan memiliki tingkat gejala depresi normal (36\%). Dengan menggunakan uji Fisher diperoleh nilai $\mathrm{p}=0.00$ yang artinya terdapat perbedaan yang bermakna antara chronotype dengan tingkat gejala depresi.

Tabel 4. Hubungan chronotype dengan tingkat depresi

\begin{tabular}{|c|c|c|c|c|c|}
\hline \multirow[t]{2}{*}{ Chronotype } & \multicolumn{4}{|c|}{ Tingkat Depresi } & \multirow[t]{2}{*}{ Total } \\
\hline & Normal & Ringan & Sedang & Parah & \\
\hline$\overline{\text { Morningness }}$ & $\begin{array}{c}35 \\
(36 \%)\end{array}$ & $\begin{array}{c}3 \\
(3 \%)\end{array}$ & 0 & $\begin{array}{c}1 \\
(1 \%)\end{array}$ & $\begin{array}{c}39 \\
(40 \%)\end{array}$ \\
\hline Eveningness & $\begin{array}{c}19 \\
(20 \%)\end{array}$ & $\begin{array}{c}26 \\
(27 \%)\end{array}$ & $\begin{array}{c}7 \\
(7 \%)\end{array}$ & $\begin{array}{c}6 \\
(6 \%)\end{array}$ & $\begin{array}{c}58 \\
(60 \%\end{array}$ \\
\hline Total & $\begin{array}{c}54 \\
(56 \%)\end{array}$ & $\begin{array}{c}29 \\
(30 \%)\end{array}$ & $\begin{array}{c}7 \\
(7 \%)\end{array}$ & $\begin{array}{c}7 \\
(7 \%)\end{array}$ & $\begin{array}{r}97 \\
(100 \%\end{array}$ \\
\hline
\end{tabular}

Uji Fisher: nilai $\mathrm{p}=0,000$ (Sumber: Data primer Juni 2019)

\section{Pembahasan}

Hasil penelitian ini menunjukkan bahwa $17 \%$ laki-laki didominasi oleh preferensi morningness. Sedangkan $46 \%$ perempuan didominasi oleh eveningness. Hasil yang didapat ini tidak sejalan dengan penelitian yang dilakukan oleh Reinaldo et al yang menyatakan bahwa mahasiswa kedokteran 
berjenis kelamin laki-laki cenderung memiliki preferensi eveningness, sedangkan mahasiswi cenderung memiliki preferensi morningness. ${ }^{17} \mathrm{Hal}$ ini dapat terjadi karena pemerataan sampel penelitian yang tidak proporsional.

Pada penelitian ini berdasarkan aspek usia juga ditemukan bahwa dari usia responden 17 hingga 21 tahun didominasi oleh individu yang memiliki preferensi eveningness. Hasil yang didapat ini memiliki kesamaan dengan penelitian yang dilakukan oleh Fischer et al yang menyatakan bahwa sebagian besar remaja memiliki chronotype eveningness. ${ }^{14}$

Berdasarkan pengaruh antara depresi dan jenis kelamin ditemukan adanya hubungan antara satu sama lain. Hasil yang didapat ini sesuai dengan penelitian yang dilakukan oleh Shams et al yang menunjukkan bahwa perempuan memiliki kecenderungan depresi yang lebih tinggi dibandingkan laki-laki. Hali ini dikaitkan dengan faktor pengaruh hormonal, dan kemudahan perempuan dalam mengungkapkan gejala depresi bahkan sekecil apapun. ${ }^{18}$

Data responden menunjukkan $44 \%$ responden dengan gejala depresi berada pada rentang usia 17-21 tahun, dimana rentang usia tersebut merupakan rentang usia peralihan menuju suatu kedewasaan. Penelitian yang dilakukan oleh National Institute of Mental Health (NIMH) yang menyebutkan bahwa prevalensi kejadian depresi berdasarkan usia yaitu usia 17-25 tahun sebesar $13,1 \%$, usia $26-49$ tahun sebesar $7,7 \%$ dan usia 50 tahun keatas sebesar 4,7\%. Dengan demikian dapat ditarik kesimpulan bahwa prevalensi tertinggi didominasi oleh kategori usia remaja. ${ }^{19}$

Hasil penelitian ini menunjukkan bahwa responden yang memiliki chronotype morningness dan tidak memiliki gejala depresi (normal) sebanyak 35 mahasiswa (36\%), sedangkan responden yang memiliki chronotype morningness dan memiliki gejala depresi sebanyak 4 mahasiswa (4\%). Selain itu, responden yang memiliki chronotype eveningness dan tidak memiliki gejala depresi (normal) sebanyak 19 mahasiswa (20\%). Sedangkan responden yang memiliki chronotype eveningness dan memiliki gejala depresi sebanyak 39 mahasiswa (40\%). Uji statistik menunjukkan bahwa terdapat hubungan yang signifikan antara chronotype dengan tingkat gejala depresi pada responden. Hal ini sesuai dengan penelitian yang dilakukan oleh $\mathrm{Au}$ dan
Reece bahwa terdapat hubungan antara chronotype dengan tingkat gejala depresi. Pada penelitian tersebut juga menyebutkan bahwa individu dengan eveningness cenderung memiliki gejala depresi dibandingkan dengan individu yang memiliki preferensi morningness. $^{20}$

Chronotype eveningness dilaporkan memiliki gangguan tidur yang buruk sehingga berdampak dengan penurunan kemampuan untuk mengendalikan, menghambat, atau mengubah tanggapan emosional. Eveningness juga diasosiasikan dengan kondisi depresi termasuk seasonal affective disorder (SAD). Pada gangguan bipolar, chronotype berhubungan dengan depresi tetapi tidak bersifat mania. Eveningness juga berkorelasi dengan gangguan tidur dan kebiasaan gaya hidup yang tidak sehat, yang mana hal tersebut dapat meningkatkan risiko terjadinya gangguan suasana hati. $^{21}$

Chronotype tidak statis, melainkan berubah sepanjang umur. Remaja prapubertas cenderung memiliki preferensi yang lebih kuat terhadap morningness, dan kemudian sebagian besar remaja bergeser ke arah eveningness selama masa remaja, diikuti oleh kembali secara perlahan menuju preferensi morningness di masa dewasa. ${ }^{21-23}$ Pubertas adalah faktor yang paling mendasari pergeseran selama masa remaja sementara prediktor potensial lainnya kurang berpengaruh. ${ }^{21,23}$ Perubahan dalam preferensi terhadap malam ini adalah normatif, namun tidak terjadi pada waktu yang sama atau pada tingkat yang sama untuk semua remaja. Kemudian, pubertas juga dikaitkan dengan peningkatan depresi, sehingga tingkat prevalensi meningkat secara signifikan untuk depresi pascapubertas dibandingkan dengan remaja prapubertas. $^{24,25}$

National Sleep Foundation merekomendasikan agar remaja tidur antara 8 dan 10 jam, tetapi hanya $15 \%$ yang melaporkan mencapai 8,5 jam pada hari kerja. $^{26}$ Adapun jam tidur malam yang tidak memadai dikaitkan dengan penurunan kepercayaan diri, fungsi akademik dan kesehatan mental secara keseluruhan. ${ }^{27,28}$ Remaja yang memiliki eveningness cenderung tidur larut kemudian dipaksa bangun lebih awal untuk bersekolah, dan akibatnya tidak mendapatkan jam tidur yang ideal dan karenanya sering menyebabkan kelelahan siang hari yang berlebihan. $^{29,30}$ Pada eveningness sering terjadi ketidakcocokan antara siklus tidur dan bangun 
dengan tuntutan sehari-hari, seperti sekolah, dan dapat menempatkan remaja pada risiko tinggi untuk hasil negatif, termasuk fungsi akademis yang buruk dan keadaan depresi. Dengan persentase remaja yang memiliki preferensi eveningness meningkat dua kali lipat dibandingkan kelompok usia lainnya. ${ }^{31}$

Keterbatasan penelitian ini adalah pengukuran depresi hanya didasarkan pada MorningnessEveningness Questionnaire dan Beck Depression Inventory II sementara terdapat faktor lain yang tidak dianalisis dalam penelitian ini seperti faktor internal contohnya Dim Light Melatonin Onset (DLMO) dan eksternal yaitu tempat tinggal, keadaan finansial, psikososial, peristiwa kehidupan dan faktor-faktor lainnya. Serta banyaknya faktor yang mempengaruhi kepribadian dalam mengekspresikan depresi. Tidak adanya data anamnesis atau wawancara yang menunjukkan secara jelas faktor penyebab depresi bagi mahasiswa.

\section{Kesimpulan}

Terdapat hubungan yang bermakna antara chronotype dengan tingkat gejala depresi pada mahasiswa kedokteran tingkat pertama di Fakultas Kedokteran Universitas Tanjungpura.

\section{Daftar Pustaka}

1. Guyton AC, Hall JE. Buku ajar fisiologi kedokteran 9th ed. Jakarta: EGC; 1997

2. Roenneberg T, Kumar CJ, Merrow M. The human circadian clock entrains to sun time. Current Biology. 2007;17(2):R44-5.

3. Gelbmann G, Kuhn NS, Pazhedath TJ, Ardeljan M, Wober C. Morningness: protective factor for sleep-related and emotional problems in childhood and adolescence? Chronobiol. Int., 2012, 29(7):898-910.

4. Roenneberg T, Wirz JA, Merrow M. Life between clocks: daily temporal patterns of human chronotypes. J Biol Rhythms. 2003;18(1):80-90.

5. Adan A, Natale V. Gender differences in morningness-eveningness preference. Chronobiology International. 2002;19(4):709-20.

6. Marion SR, Zeitoune R, Lúcia CB, Martino M, Prestes F, Loro M. Chronotype and work shift in nursing workers of university hospitals. 2017;70(5):958-64.

7. Kivelä L, Papadopoulos MR, Antypa N. Chronotype and Psychiatric Disorders. Current Sleep Medicine Reports. 2018;4(2):94-103.

8. Kim SM, Kang SH, Yoon IY, Kim CH, Lim MH, Paik $\mathrm{KC}$, et al. Restless legs syndrome and morningness-eveningness in the Korean high-school students. Sleep Medicine Research. 2016;7(2):55-9.

9. Reid KJ, Baron KG. Circadian misalignment and health. International Review of Psychiatry. 2014;26(2):139-54.
10. Maslim, R. Buku saku diagnosis gangguan jiwa rujukan ringkas dari PPDGJ - III dan DSM 5. Jakarta : FK Unika Atma Jaya; 2013.

11. World Health Organization. Depression and other common mental disorders: global health estimates. Switzerland: World Health Organization. 2012.www.who.int/healthinfo/global_burden_diseaseDiakses pada Februari 2019.

12. Kemenkes RI. Riset Kesehatan Dasar; RISKESDAS. Jakarta: Balitbang; 2018.

13. Torpy JM, Burke AE, Glass RM. Depression. JAMA. 2010;303(19):1994.

14. Shams-Eldin AA, Hassan H, Elkhar OS, Amer S, Kasim K. Prevalence of depression among medical students at Al-Azhar University: a cross sectional study. J Community Med Public Health .2017;2017(3):1-7.

15. Hariyanto AD, Surjadi C, Joewana S. Prevalensi depresi dan faktor yang mempengaruhi pada mahasiswa fakultas kedokteran universitas katolik Indonesia atma jaya angkatan 2007 [skripsi]. [Jakarta]: Fakultas Kedokteran Universitas Katolik Indonesia Atma Jaya; 2010.

16. Carskadon, M.A.; Dement, W.C. Principles and practice of sleep medicine. 4th ed. Philadelphia : Elsevier Saunders. 2005. p.13-23.

17. Reinaldo Maximo Gomes J, Karine Ferreira Santos F, Filipe Melo de Freitas I, Ferreira de Oliveira I, Aguida dos Santos H, Da Silva J, et al. The assessment of medical students' chronotypes. World J Neurosci. 2017;7(3):275-81.

18. Fischer D, Lombardi DA, Marucci-Wellman H, Roenneberg T. Chronotypes in the US - Influence of age and sex. PloS One. 2017;12(6):e0178782

19. National Institute of Mental Health (NIMH). Prevalence of major depressive episode among adults. https://www.nimh.nih.gov/health/statistics/ major-depression.shtml diakses tanggal 21 maret 2019.

20. Au J, Reece J. The relationship between chronotype and depressive symptoms: A meta-analysis. J Affect Disord. 2017;218:93-104.

21. Alvaro PK, Roberts RM, Harris JK. The independent relationships between insomnia, depression, subtypes of anxiety, and chronotype during adolescence. Sleep Med. 2014;15(8):934-41.

22. Sheaves B, Porcheret K, Tsanas A, Espie CA, Foster RG, Freeman D, et al. Insomnia, nightmares, and chronotype as markers of risk for severe mental illness: results from a student population. Sleep. 2016;39(1):173-81.

23. Kim S, Dueker GL, Hasher L, Goldstein D. Children's time of day preference: age, gender and ethnic differences. Personal Individ Differ. 2002;33(7):1083-90

24. Roenneberg T, Kuehnle T, Pramstaller PP, Ricken J, Havel M, Guth A, Merrow M. A marker for the end of adolescence. Current Biology. 2004;14(24):R1038.

25. Merikangas KR, He J-P, Burstein M, Swanson SA, Avenevoli S, Cui L, et al. Lifetime prevalence of mental disorders in U.S. adolescents: results from the National Comorbidity Survey Replication--Adolescent Supplement (NCS-A). J Am Acad Child Adolesc Psychiatry. 2010;49(10):980-9.

26. Hankin BL, Young JF, Abela JRZ, Smolen A, Jenness JL, Gulley LD, et al. Depression from childhood into late adolescence: influence of gender, development, genetic susceptibility, and peer stress. J Abnorm Psychol. 2015;124(4):803-16. 
27. Fredriksen K, Rhodes J, Reddy R, Way N. Sleepless in Chicago: tracking the effects of adolescent sleep loss during the middle school years. Child Dev. 2004;75(1):84-95.

28. Roberts RE, Roberts CR, Duong HT. Sleepless in adolescence: prospective data on sleep deprivation, health and functioning. J Adolesc. 2009;32(5):1045-57.

29. Randler C, Bilger S, Díaz-Morales JF. Associations among sleep, chronotype, parental monitoring, and pubertal development among german adolescents. J Psychol. 2009;143(5):509-20.

30. Taillard J, Philip P, Bioulac B. Morningness/eveningness and the need for sleep. J Sleep Res. 1999;8(4):291-5.

31. Vollmer C, Schaal S, Hummel E, Randler C. Association among school- related, parental and self-related problems and morningness-eveningness in adolescents. Stress Health. 2011;27(5):413-9. 